\title{
A comparative study between local bone graft with or without cages in unilateral posterior lumbar interbody fusion (PLIF): a retrospective study
}

\section{Tao Jiang He}

Affiliated Hospital of North Sichuan Medical College

Jun-fei Feng ( $\sim 13438778787 @ 163 . c o m$ )

Affiliated Hospital of North Sichuan Medical College

Qian Chen

Affiliated Hospital of North Sichuan Medical College

Yang Yang

Affiliated Hospital of North Sichuan Medical College

Qing-song Zhou

Affiliated Hospital of North Sichuan Medical College

Kai-xin Liu

Affiliated Hospital of North Sichuan Medical College

\section{Research article}

Keywords: Posterior lumbar interbody fusion, Local bone graft, cage, Spinal fusion

Posted Date: September 18th, 2020

DOl: https://doi.org/10.21203/rs.3.rs-70037/v1

License: (9) (i) This work is licensed under a Creative Commons Attribution 4.0 International License.

Read Full License 


\section{Abstract \\ Objective}

A retrospective study of the clinical and radiological results between local bone graft with a cage and without cage in patients treated with unilateral fixation and posterior lumbar interbody fusion surgery.

\section{Methods}

A total of 52 patients who underwent PLIF in our institution were evaluated from January 2015 to January 2018. 30 of these patients received PLIF with local bone graft combined with using one cage, and 22 patients received PLIF with local bone graft without using cage. The clinical data and perioperative complications of the two groups were recorded. X-ray were taken before, after operation and at the end of follow-up to calculate the height of intervertebral disc and the fusion rate. SUK's criteria were used to evaluate the quality of spinal fusion at the follow-up time. The results between the cage and noncage group were compared.

\section{Results}

There was no statistical difference in baseline data between the two groups, and The mean follow-up time was 18.43 months in cage group and 17.50 months in non- cage group $(P=0.553)$. In additions, the significant difference was not found in the comparison of perioperative evaluation data between the two groups, such as operation time $(P=0.299)$, blood loss $(P=0.342)$ and incidence of complications $(P=$ 1.000). Furthermore, the significant difference of VAS score cannot be found in preoperation $\left(P_{\text {leg }}=0.731\right.$, $\left.P_{\text {lowback }}=0.786\right)$, postoperation $\left(P_{\text {leg }}=0.534, P_{\text {lowback }}=0.725\right)$ and the final follow-up $\left(P_{\text {leg }}=0.654\right.$, $\left.P_{\text {lowback }}=0.362\right)$ between the two groups. The same results were also obtained in the comparison of ODI index $\left(P_{\text {pre }}=0.682, P_{\text {final }}=0.712\right)$ and intervertebral height $\left(P_{\text {post }}=0.363, P_{\text {final }}=0.094\right)$. The final fusion rates were $96.7 \%$ (cage group) and $86.4 \%$ (non- cage group) respectively, and there was no statistical difference $(P=0.553)$.

\section{Conclusion}

Local bone graft has the same advantages as a cage in unilateral PLIF. Comparing with local bone graft using cage, we believe that the local bone graft is a more ideal way in unilateral PLIF, and decrease operation cost.

\section{Introduction}


Degenerative disease of lumbar intervertebral disc is a common disease in adults ${ }^{[1]}$, and often leads to symptoms such as low back, lower extremity pain or sensory disorders. Some patients with severe symptoms often need surgical treatment ${ }^{[2]}$. According to related studies, degenerative lumbar disc herniation is caused by the decrease of water content of intervertebral disc and the decrease of tensile strength of annulus fibrosus ${ }^{[3]}$. Lumbar interbody fusion is suitable for patients with pain or vertebral instability ${ }^{[4]}$. Posterior lumbar interbody fusion (PLIF) has always been considered as a classical surgical method for the treatment of this lumbar degenerative disease ${ }^{[5]}$. In order to perform posterior lumbar interbody fusion (PLIF), most of the bones needed in traditional fusion come from autogenous iliac bone ${ }^{[6]}$. However, autogenous iliac bone transplantation often brings many complications, among which long-term pain in the ilium is the most frequently reported ${ }^{[7]}$. In recent years, intervertebral fusion cage has been widely used, and it has been widely reported in the relevant literature that good clinical results have been obtained ${ }^{[8]}$. However, the non-absorbable character of cage itself may increase the risk of long-term complications and even require surgical intervention to remove implants ${ }^{[9,10]}$. In order to avoid these

problems, Simmons et al. ${ }^{[6,11-13]}$ adopted local bone graft instead of grafting with cage and achieved the same effect.

The purpose of this study was to determine whether local bone grafting and cage bone grafting have the same effect in the treatment of lumbar disc herniation with unilateral PLIF.

\section{Materials And Methods}

A total of 52 patients who underwent PLIF in our institution (the affiliated hospital of the college) were evaluated from January 2015 to January 2018. The study protocol was ethically approved by the Human Research Ethics Committee of the institution. Prior written informed consent was obtained from all study participants. 30 of these patients received PLIF with local bone graft combined with using one cage, and 22 patients received PLIF with local bone graft without using cage. Explain the disadvantages and advantages of the operation to the patient before the operation, and the patient will choose the operation method. The clinical data of the patients were recorded and displayed in Table 1. Inclusion criteria: disc hernia result in persistent low back pain and/or sciatica after routine conservative treatment (more than 6 months); Unilateral lumbar disc herniation confirmed by imaging examination; Medical records and imaging images are complete and reliable.

\section{Surgical procedure}

All patients were treated with general anesthesia and prone position after complete anesthesia. The soft tissue was cut layer by layer until the spinous process and bilateral laminae were fully exposed. The spinous process and lamina were resected with an osteotome to destroy the superior and inferior articular process joints and cartilage of the vertebral body. The removed lamina and spinous process were cut into small bone slices by the assistant. In cage group, bone slices were first implanted into the intervertebral disc space, and then cage filled with local bone transplantation was implanted into the intervertebral disc 
space. In the non- cage group, the smaller bone pieces were inserted into the intervertebral disc space, and then the large blocks were implanted. Finally, pedicle screws were placed and connecting rods were installed.

\section{Follow-ups and radiological assessment}

The operation time, blood loss and the complications were noted after operation. One week after operation, the height of intervertebral space was recorded by X-ray, and VAS score were collected at the same time. The degree of intervertebral fusion was assessed by dynamic X-ray at the final follow-up, and the SUK's criteria ${ }^{[14]}$ were used to evaluate the quality of spinal fusion (Table 1).

Table 1 The criteria for judging bone graft fusion

\begin{tabular}{|ll|}
\hline Grade & Description \\
\hline Excellent & $\begin{array}{l}\text { continuous trabecular formation could be seen in the fusion segment, the relative motion } \\
\text { of the dynamic position X-ray was less than } 4 \mathrm{~mm}\end{array}$ \\
\hline good & $\begin{array}{l}\text { fuzzy bone trabeculae could be seen in the fusion segment, the relative activity of the } \\
\text { dynamic position X-ray was less than } 4 \mathrm{~mm}\end{array}$ \\
\hline poor & $\begin{array}{l}\text { no bone trabeculae were found in the fusion segment, the relative activity of the dynamic } \\
\text { position X-ray }>4 \mathrm{~mm}\end{array}$ \\
\hline
\end{tabular}

\section{Statistical analysis}

Statistical analysis was performed by using SPSS 24.0 , and all data were expressed as mean \pm standard deviation (SD). The data of VAS score, ODI index, intervertebral height, operation time and blood loss were statistically analyzed by Student's $t$ test. The incidence of complications and fusion rate were calculated by Fisher exact probability test. A value of $P<0.05$ was considered as statistically significant.

\section{Results}

There was no significant difference in clinical baseline data such as age $(t=1.448, P=0.157)$, $\operatorname{sex}\left(\chi^{2}=\right.$ $0.071, P=0.790), \mathrm{BMI}(t=0.500, P=0.619)$, diseased segment $\left(\chi^{2}=0.180, P=0.964\right)$ and preoperative pain score(VAS score of low back pain: $t=0.273, P=0.786$; VAS score of leg: $t=0.346, P=0.731$ ) between the two groups. The follow-up period ranged from 11 to 32 months $(18.43 \pm 5.86)$ in cage group and 12 to 30 months $(17.50 \pm 5.14)$ in non- cage group respectively. The difference was not found to be significant between the two groups $(P=0.553)$. The fusion rates of the two groups were $96.7 \%$ (cage) and $86.4 \%$ (non- cage) respectively, and there was no statistical difference between the two group $(P=0.299)$ (Table 2).

Table 2. Demographic characteristics of the two groups 


\begin{tabular}{|llll|}
\hline & $\begin{array}{l}\text { Cage group } \\
(\boldsymbol{n}=\mathbf{3 0})\end{array}$ & $\begin{array}{l}\text { Non- cage group } \\
(\boldsymbol{n}=\mathbf{2 2})\end{array}$ & $\boldsymbol{P}$ \\
\hline Age (years) & $53.33 \pm 10.19$ & $59.00 \pm 16.15$ & 0.157 \\
\hline Gender & & & 0.790 \\
\hline Male & 18 & 14 & \\
\hline Female & 12 & 8 & 0.964 \\
\hline Segment & & & \\
\hline L3/4 & 4 & 3 & 0.619 \\
\hline L4/5 & 14 & 11 & 0.553 \\
\hline L5/S1 & 12 & 8 & 1.000 \\
\hline BMI (kg/m ${ }^{2}$ ) & $24.05 \pm 2.87$ & $24.39 \pm 1.63$ & 0.299 \\
\hline Follow-up time (months) & $18.43 \pm 5.86$ & $17.50 \pm 5.14$ & \\
\hline Incidence of complications (\%) & $3.3 \%$ & $4.5 \%$ & $86.4 \%$ \\
\hline Fusion rate (\%) & $96.7 \%$ & & \\
\hline
\end{tabular}

\section{Operation time and blood loss}

The mean operation time was $73.80 \pm 9.60 \mathrm{~min}$ (ranged $48.00-96.00 \mathrm{~min}$ ) with an average blood loss volume of $292.33 \pm 20.63 \mathrm{ml}$ (ranged $250.00-330.00 \mathrm{ml}$ ) in cage group. The average operation time was $70.91 \pm 10.08 \mathrm{~min}$ (ranged 42.00-90.00 $\mathrm{min}$ ) and the blood loss volume were $304.55 \pm 25.95 \mathrm{ml}$ (ranged 240.00-340.00 ml) in non- cage group. There was no significant difference in the above data between the two groups $(P=0.299$ and $P=0.064)$.

\section{Complications, VAS score and the height of intervertebral space}

One complication occurred in each of the two groups, and both of them were superficial wound infection. No significant difference was found for the perioperative complications between the two groups $(P=$ 1.000). The mean VAS score of low back pain was $3.90 \pm 0.88$ (ranged 2.00-5.00) and leg pain was 3.03 \pm 1.03 (ranged 1.00-6.00) in cage group. The average VAS score of low back pain was $4.00 \pm 1.15$ (ranged 1.00-6.00) and leg pain was 3.23 \pm 1.19 (ranged 1.00-5.00) in non- cage group. There was no significant difference in the above VAS score between the two groups $(P=0.725$ and $P=0.534)$. Same as before, no significant difference was found for the height of intervertebral space between the cage (10.26 $\pm 0.66 \mathrm{~mm})$ and non- cage group $(10.09 \pm 0.68 \mathrm{~mm})$. The mean VAS score of final follow-up of low back pain was $0.97 \pm 0.67$ (ranged $0.00-2.00$ ) and leg pain was $1.07 \pm 0.52$ (ranged $0.00-2.00$ ) in cage group. The average VAS score of low back pain was $1.13 \pm 0.64$ (ranged $0.00-2.00$ ) and leg pain was $1.00 \pm$ 
0.53 (ranged 1.00-2.00) in non- cage group. There was no significant difference in the final follow-up VAS score between the two groups $(P=0.362$ and $P=0.654)$. Meanwhile, the significant difference was not found for the ODI index and intervertebral space height among the cage (ODI: $11.83 \pm 3.28$, intervertebral height: $9.91 \pm 0.47 \mathrm{~mm}$ ) and non- cage group (ODI: $11.50 \pm 3.08$, intervertebral height: $9.65 \pm$ $0.61 \mathrm{~mm})$.

\section{Discussion}

Posterior lumbar interbody fusion (PLIF) is an effective surgical method for the treatment of degenerative lumbar disc herniation ${ }^{[5]}$. In 1991, Hambly et al. ${ }^{[15]}$ took the lead in using unilateral pedicle screw combined with autogenous bone graft fusion to treat patients with lumbar degeneration, and the final follow-up of the patients with bone graft fusion rate was $85 \%$. A number of subsequent studies have shown that unilateral pedicle screw fixation is weaker than bilateral fixation, but it can effectively reduce the stress shielding of fusion segments and create more favorable conditions for fusion. and it also has obvious advantages in operation time, blood loss, hospitalization cost, etc. ${ }^{[16]}$

The effective fusion of spinal intervertebral bone graft in PLIF operation is an important index to evaluate the long-term effect. some studies suggest that successful intervertebral bone graft fusion will bring better functional results and better overall satisfaction to patients ${ }^{[17,18]}$. Christensen et al. ${ }^{\left[{ }^{1}, 18\right]}$ believe that once unstable segmental fusion is successful, the symptoms of low back pain can be significantly alleviated. In spinal fusion surgery, a suitable graft material is often needed to induce the formation of new bone at the operative site ${ }^{[19]}$. With the development of medical biomaterials technology, interbody fusion cage has been widely used in clinic, and the purpose of cage is to provide a sufficient fusion environment for bone graft, so as to accelerate postoperative rehabilitation and fusion ${ }^{[20]}$. Cage can be easily sterilized and stored, which greatly reduces the risk of diseases transmitted by allogeneic bone transplantation. In the case of vertebral body collapse caused by intervertebral disc degeneration, interbody fusion with cage can effectively share the load of the anterior column of the vertebral body and restore the height of the intervertebral space ${ }^{[21]}$. Although numerous analyses have confirmed that the use of cage has achieved good clinical results, cage still has many inherent shortcomings. Such as the insertion of fusion cage to reduce the available contact area of bone fusion, increase the probability of infection, increase the cost of hospitalization and so on. Closkey ${ }^{[22]}$ suggest that in order to achieve good bone graft fusion effect, more than $30 \%$ of the endplate surface area should be in direct contact with the local bone, and the use of cage often reduces the bone contact area in the fusion area. Studies have also shown that cage is a foreign body that may increase the risk of infection or immune problems in patients ${ }^{[23]}$. Lazennec ${ }^{[24]}$ has reported the risks of cage subsidence and corrosion in long-term animal model studies. In addition, cage is still an obstacle to use in developing countries such as China because of its high cost. However, the traditional intervertebral bone graft materials are often taken from the patient's autogenous ilium. although this method has the advantages of low surgical cost and increased bone contact area, some studies have pointed out that this method is often accompanied by a serious incidence of donor sites. Up to $6 \% \varangle 39 \%$ of patients have persistent pain associated with the donor site of 
the transplanted bone ${ }^{[7]}$. Simmons ${ }^{[11]}$ suggested that the laminae and spinous processes removed during the operation be given to a qualified technician who cuts them into corticocancellous pieces measuring 2-4 mm, ensuring that each chip has a cancellous side. These chips are implanted into the intervertebral disc space. Recent studies have also shown that local bone fragments obtained by laminectomy are used as bone grafts for PLIF, resulting in the same fusion rate as autogenous iliac bone ${ }^{[6,12]}$. However, some people do not agree with this view. Abdul ${ }^{[21]}$ found that the increase of intervertebral disc height and VAS score in the intervertebral fusion cage group was significantly better than that in the local bone graft group in the treatment of lumbar degenerative spondylolisthesis $\left(\mathbb{\square}^{\circ} / \mathbb{\bigotimes}^{\circ}\right)$ with PLIF operation.

Though the similar clinical results were obtained from both of the groups for single level PLIF in the present study, we still believe that local bone grafts without cages have more advantages than those with cages. The main reasons are as the following: The non-use of cage can significantly reduce the cost of surgery for patients, which is particularly important for many developing countries. Although cage has good biocompatibility, it is still a foreign matter and has potential risks.

In conclusion, local bone graft has the same advantages as bone graft fusion cage in unilateral PLIF. Comparing with local bone graft using a single cage, we believe that the purely local bone graft is a more ideal way in unilateral PLIF.

\section{Abbreviations}

Posterior lumbar interbody fusion (PLIF)

Visual analog scale (VAS)

Oswestry disability index (ODI)

Body mass index (BMI)

\section{Declarations}

\section{Ethics approval and consent to participate}

This study has been approved by the Institutional Review Board at the Affiliated Hospital of North Sichuan Medical College. Each author certifies that all investigations were conducted in accordance with ethical principles. The participant involved in the study gave their informed consent and signed and informed consent form.

\section{Consent for publication}

Written consent to publish this information was obtained from study participants. Proof of consent to publish from study participants can be requested at any time. 
Availability of data and materials

All data analyzed during this study are included within the manuscript. The datasets used and/or analyzed during this study are available from the first author on reasonable request.

\section{Competing interests}

The authors announce that they do not have any competing interests.

\section{Funding}

No commercial, public, or nonprofit organizations financially supported this research.

\section{Authors' contributions}

JFF, QC and JTH designed this study. JFF, QC and YY were responsible for gathering, analyzing and interpreting data, and writing the manuscript. JTH, QSZ and KXL provided the valuable case, performed the operation and made contributions to revising the manuscript for crucial intellectual content. The final version of the text has been reviewed and approved by all authors.

\section{Acknowledgements}

We are grateful to the staff of our department for their support and contribution in this study.

\section{References}

1. Patel DV, Yoo JS, Karmarkar SS, et al. Interbody options in lumbar fusion[J]. Journal of Spine Surgery,2019,5(S1):S19-S24.

2. Müslüman AM, Yılmaz A, Cansever T, et al. Posterior lumbar interbody fusion versus posterolateral fusion with instrumentation in the treatment of low-grade isthmic spondylolisthesis: midterm clinical outcomes[J]. Journal of Neurosurgery: Spine,2011,14(4):488-496.

3. Du Bois M, Szpalski M, Donceel P. Patients at risk for long-term sick leave because of low back pain[J]. The Spine Journal,2009,9(5):350-359.

4. Messner A, Stelzeneder D, Trattnig S, et al. Does T2 mapping of the posterior annulus fibrosus indicate the presence of lumbar intervertebral disc herniation? A 3.0 T magnetic resonance study[J]. Eur Spine J. 2017;26(3):877-83.

5. Li L, Liu Y, Zhang P, et al. Comparison of posterior lumbar interbody fusion with transforaminal lumbar interbody fusion for treatment of recurrent lumbar disc herniation: A retrospective study [J]. J int Med Res. 2016;44(6):1424-9. 
6. Ito Z, Imagama S, Kanemura T, et al. Bone union rate with autologous iliac bone versus local bone graft in posterior lumbar interbody fusion (PLIF): a multicenter study[J]. European Spine Journal,2013,22(5):1158-1163.

7. Sheha ED, Meredith DS, Shifflett GD, et al. Postoperative pain following posterior iliac crest bone graft harvesting in spine surgery: a prospective, randomized trial[J]. The Spine Journal. 2018;18(6):98692.

8. Christensen FB, Hansen ES, Eiskjaer SP, et al. Circumferential lumbar spinal fusion with Brantigan cage versus posterolateral fusion with titanium Cotrel-Dubousset instrumentation: a prospective, randomized clinical study of 146 patients[J]. Spine (Phila Pa 1976),2002,27(23):2674-2683.

9. Tullberg T. Failure of a carbon fiber implant. A case report[J]. Spine,1998,23(16):1804-1806.

10. Togawa D, Bauer TW, Lieberman IH, et al. Lumbar intervertebral body fusion cages: histological evaluation of clinically failed cages retrieved from humans[J]. J Bone Joint Surg Am,2004,86$A(1): 70-79$.

11. Simmons JW. Posterior lumbar interbody fusion with posterior elements as chip grafts[J]. Clinical orthopaedics and related research,1985(193):85-89.

12. Ito Z, Matsuyama Y, Sakai Y, et al. Bone Union Rate With Autologous Iliac Bone Versus Local Bone Graft in Posterior Lumbar Interbody Fusion[J]. Spine,2010,35(21): E1101-E1105.

13. Miura Y, Imagama S, Yoda M, et al. Is Local Bone Viable as a Source of Bone Graft in Posterior Lumbar Interbody Fusion? [J]. Spine,2003,28(20):2386-2389.

14. Suk SI, Lee CK, Kim WJ, et al. Adding posterior lumbar interbody fusion to pedicle screw fixation and posterolateral fusion after decompression in spondylolytic spondylolisthesis[J]. Spine,1997,22(2):210-219.

15. Hambly MF, Wiltse LL, Peek RD, et al. Unilateral lumbar fusion[J]. Spine (Phila Pa 1976),1991,16(6 Suppl): S295-S297.

16. Han Y, Liu Z, Wang S, et al. Comparison of unilateral versus bilateral pedicle screw fixation in degenerative lumbar diseases: a meta-analysis[J]. European Spine Journal,2014,23(5):974-984.

17. Yu C, Wang C, Chen P. Instrumented Posterior Lumbar Interbody Fusion in Adult Spondylolisthesis[J]. Clinical Orthopaedics and Related Research,2008,466(12):3034-3043.

18. Wetzel FT, Brustein M, Phillips FM, et al. Hardware failure in an unconstrained lumbar pedicle screw system. A 2-year follow-up study[J]. Spine,1999,24(11):1138-1143.

19. Lementowski PW, Lucas P, Taddonio RF. Acute and Chronic Complications of Intracortical Iliac Crest Bone Grafting Versus the Traditional Corticocancellous Technique for Spinal Fusion Surgery[J]. Orthopedics,2010,33(4).

20. Fogel GR, Toohey JS, Neidre A, et al. Is One Cage Enough in Posterior Lumbar Interbody Fusion: A Comparison of Unilateral Single Cage Interbody Fusion to Bilateral Cages[J]. Journal of Spinal Disorders Techniques. 2007;20(1):60-5. 
21. Abdul QR, Qayum MS, Saradhi MV, et al. Clinico-radiological profile of indirect neural decompression using cage or auto graft as interbody construct in posterior lumbar interbody fusion in spondylolisthesis: Which is better? [J]. Journal of Craniovertebral Junction Spine. 2011;2(1):12.

22. Closkey RF, Parsons JR, Lee CK, et al. Mechanics of interbody spinal fusion. Analysis of critical bone graft area[J] Spine. 1993;18(8):1011.

23. Jockisch KA, Brown SA, Bauer TW, et al. Biological response to chopped-carbon-fiber-reinforced peek[J]. Journal of Biomedical Materials Research,1992,26(2):133-146.

24. Lazennec JY, Madi A, Rousseau MA, et al. Evaluation of the 96/4 PLDLLA polymer resorbable lumbar interbody cage in a long term animal model[J]. European Spine Journal,2006,15(10):1545-1553.

\section{Figures}
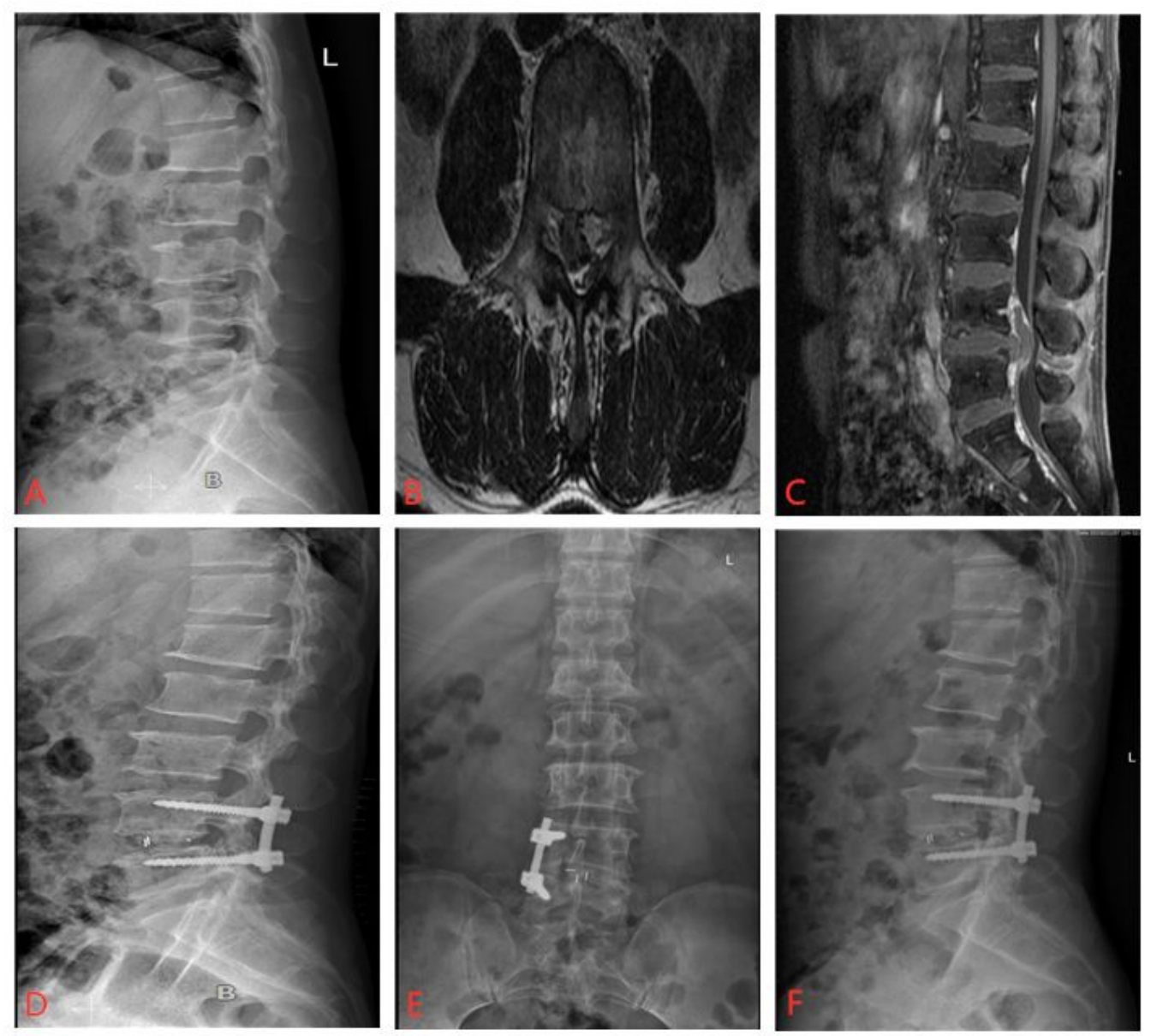

Figure 1 
Cage group: Pictures A, B and C show the preoperative intervertebral space and herniated disc. D, E and F show the X-ray images of the postoperative and the final follow-up respectively.
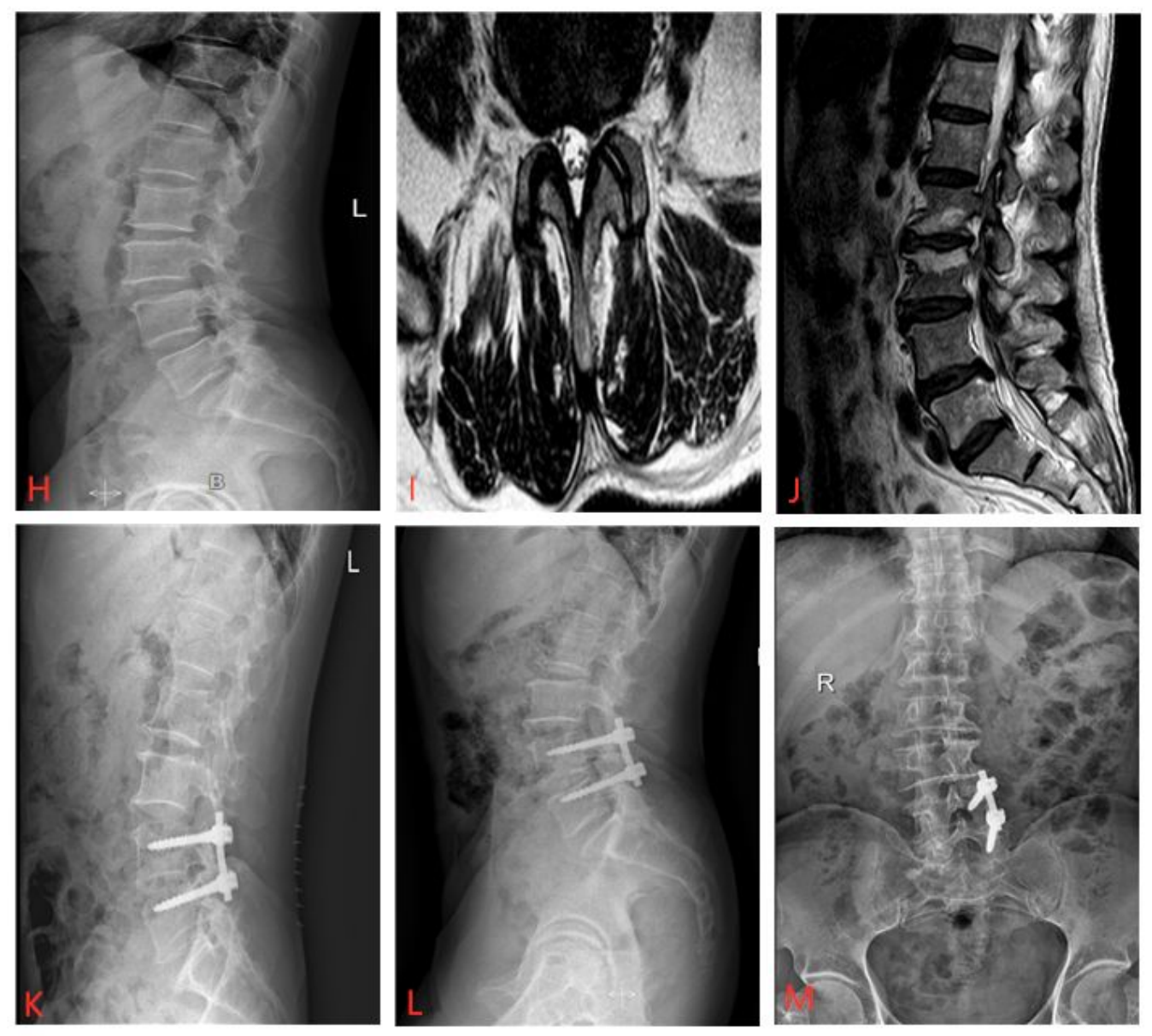

Figure 2

Non-cage group: Pictures $\mathrm{H}, \mathrm{I}$ and $\mathrm{J}$ show the preoperative intervertebral space and herniated disc. $\mathrm{K}, \mathrm{L}$ and $\mathrm{M}$ show the $\mathrm{X}$-ray images of the postoperative and the final follow-up respectively. 

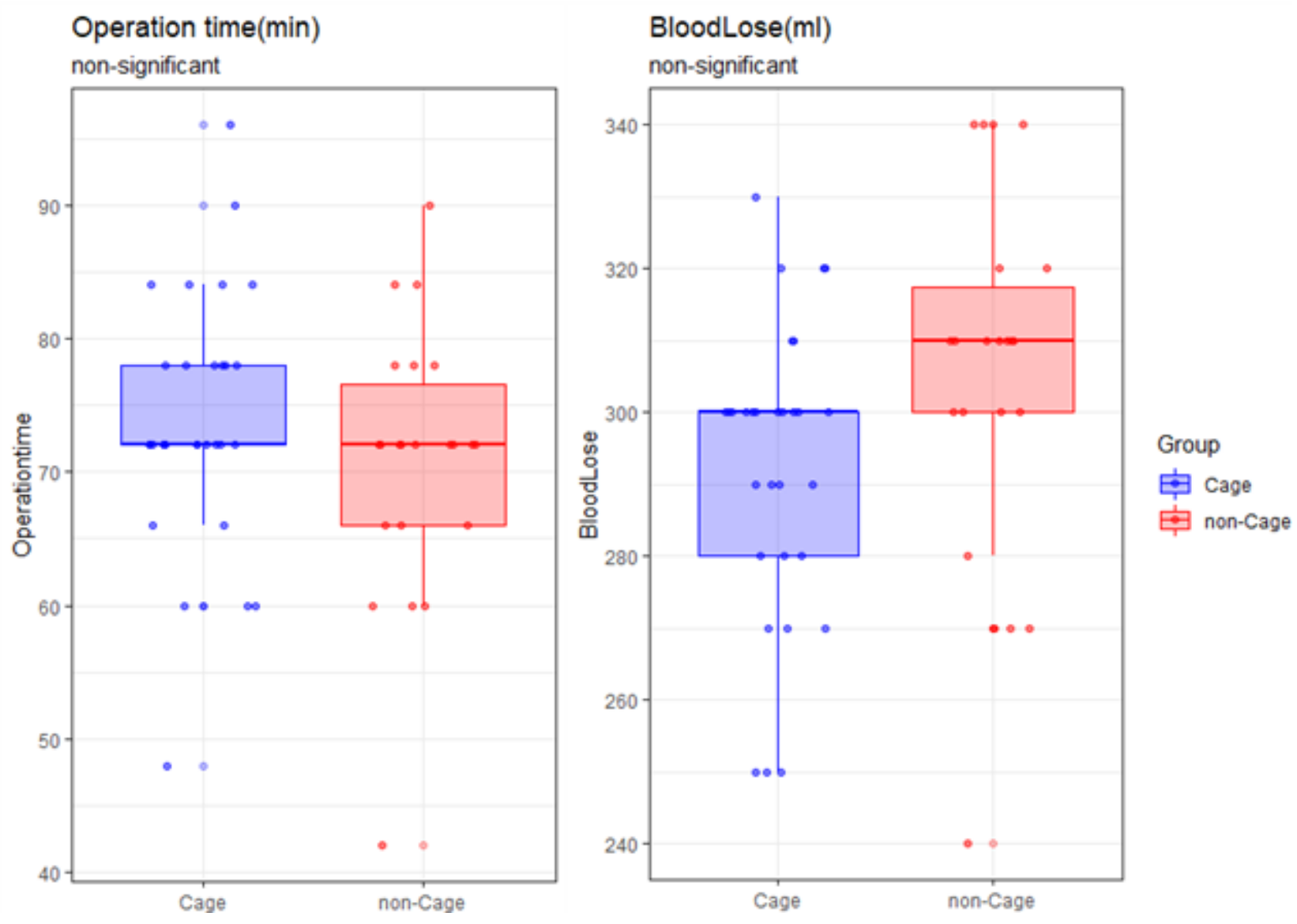

Figure 3

Box-plot showed that there was no statistical difference in operation time and blood loss between Cage and non-Cage group. 


\section{VAS score}

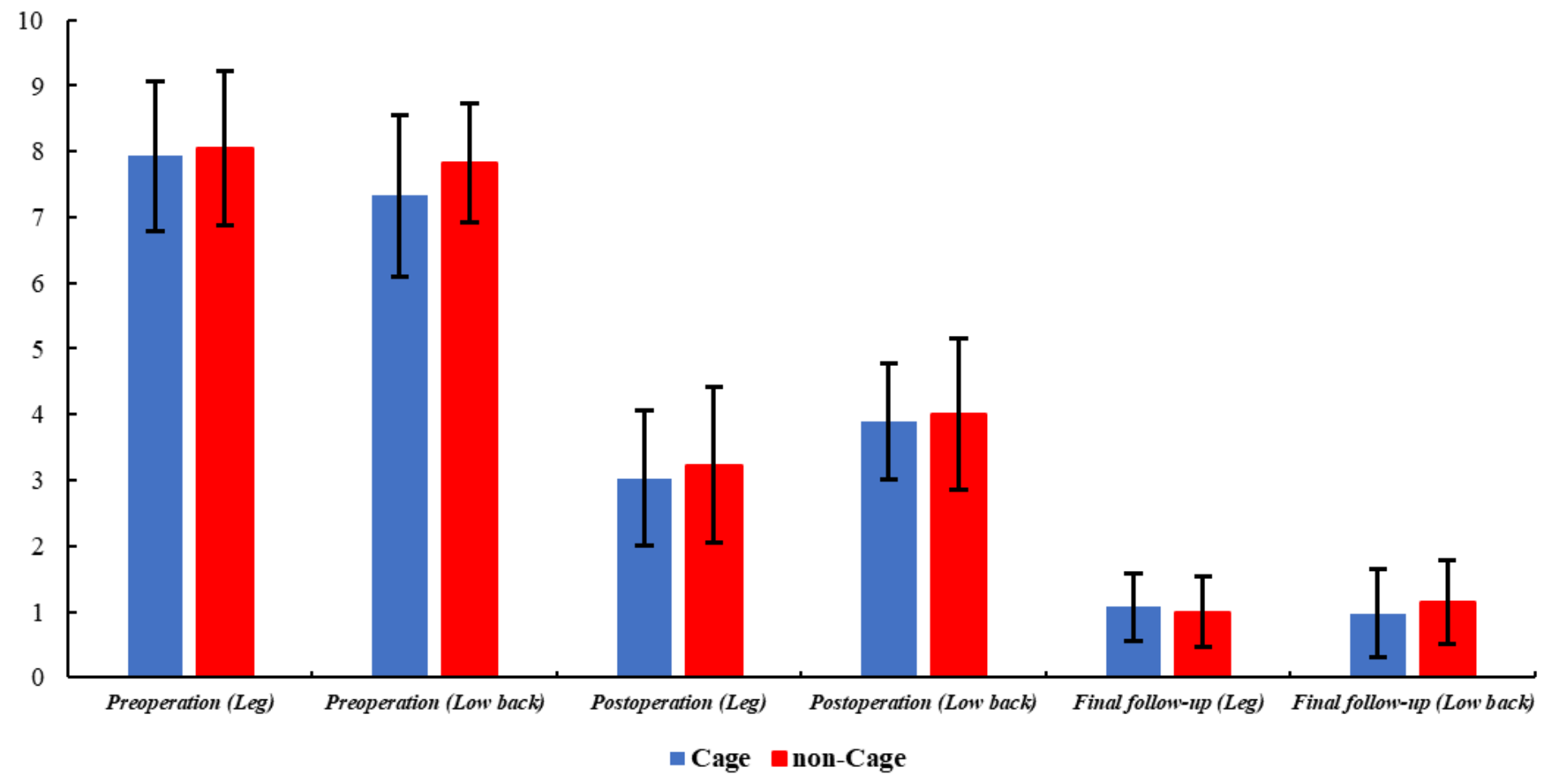

Figure 4

There was no significant difference of VAS score in preoperation, postoperation and the final follow-up between Cage and non-Cage group.

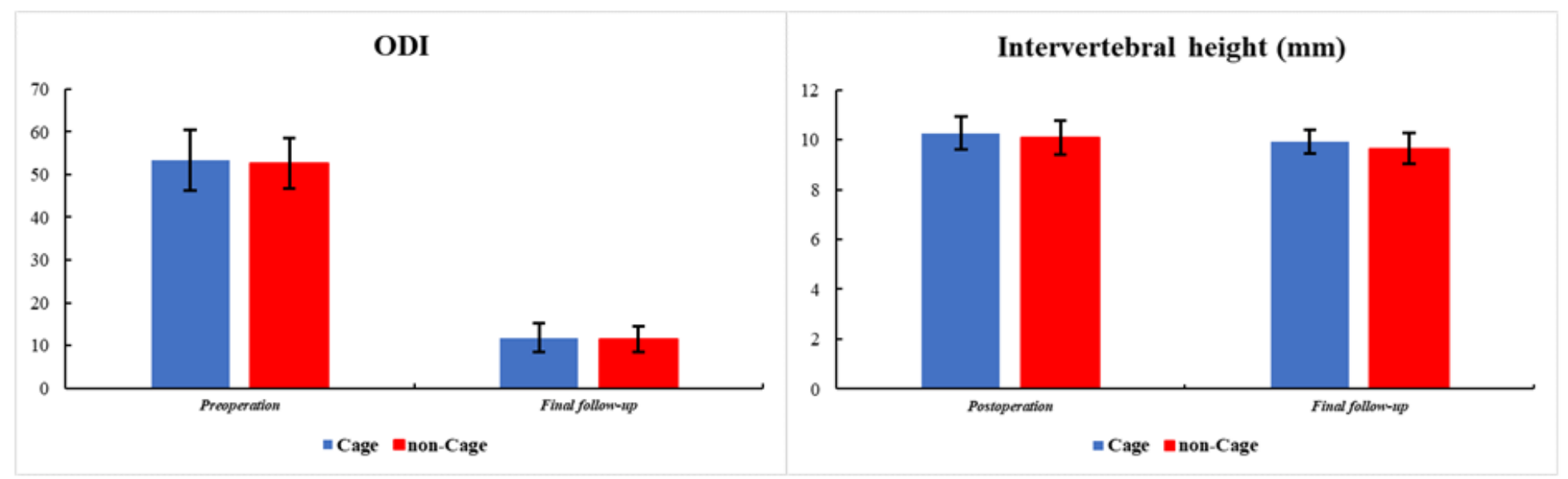

Figure 5

There was no significant difference of ODI and intervertebral height between Cage and non-Cage group. 